\title{
Optimization of Fuel Injection Control System of Two-Stroke Aeroengine of UAV
}

\author{
Yixuan Wang, ${ }^{1}$ Yan Shi $\mathbb{D}^{1,2}$ Maolin Cai, ${ }^{1}$ Weiqing Xu $\mathbb{D}^{1},{ }^{1}$ Jian Zhang, ${ }^{1}$ Wei Zhong, ${ }^{2,3}$ \\ and Na Wang $\mathbb{D}^{1}$ \\ ${ }^{1}$ School of Automation Science and Electrical Engineering, Beihang University, Beijing 100191, China \\ ${ }^{2}$ Jiangsu Provincial Key Laboratory of Advanced Manufacture and Process for Marine Mechanical Equipment, \\ Zhenjiang 212003, China \\ ${ }^{3}$ School of Mechanical Engineering, Jiangsu University of Science and Technology, Zhenjiang 212003, China
}

Correspondence should be addressed to Yan Shi; yesoyou@gmail.com and Na Wang; lion_na987@buaa.edu.cn

Received 1 May 2020; Accepted 8 June 2020; Published 9 July 2020

Guest Editor: Juan Sandoval

Copyright ( 2020 Yixuan Wang et al. This is an open access article distributed under the Creative Commons Attribution License, which permits unrestricted use, distribution, and reproduction in any medium, provided the original work is properly cited.

Power efficiency of two-stroke spark-ignition engine is generally low because improper amount of fuel injection leads to a lot of unburned fuel loss during the engine working process. However, parameters of the fuel injection system are hard to confirm by aviation experiments due to expensive test costs. This paper proposes a method of calibrating injection parameters of two-stroke spark-ignition engine based on thermodynamic simulation and parameter optimum algorithm. Firstly, the one-dimensional thermodynamic model is built according to the internal structure and thermodynamic process of the engine; then, the model parameters are corrected according to the operating principle of the injector; after experimental verification of the model, considering both the engine power sufficiency and fuel economy, Analytic Hierarchy Process method is applied to look for the optimal injection amount and fuel injection advance angle at different engine working speeds; finally, an aeroengine experiment station with an electronic fuel injector system is built. Through simulation and experiment studies, it can be seen that when the engine speed changes from 3000 to $3500 \mathrm{RPM}$, the oil consumption rate of the optimal results is higher than that of the previous ones; when the aeroengine speed is higher than 4000 RPM, the oil consumption rate results of the optimal method are $10 \%$ to $27 \%$ higher than the original results. This paper can be a reference in the optimization of UAV aircraft engine.

\section{Introduction}

Two-stroke engine has been widely applied in the power system of small aerial equipment fuel-powered UAV because of the advantages of strong explosive and small size [1]. However, model selection of engine is always difficult for the design of fuel-powered UAV's power system. That is because, in the flight simulation environment of UAV, the output characteristics of the engine are hard to accurately predict, especially it is hard to find a matching fuel supply system. Traditional fuel supply method for two-stroke engine is using carburetor which can mechanically atomize fuel during the engine working process [2]. Nevertheless, automatic control cannot be achieved in engine with a carburetor, and the engine can hardly automatically adapt to the flight condition variation of UAV. Electronic fuel injector (EFI) has been widely developed in the area of engine fuel supply due to its superiorities of controllability and favourable characteristics [3]. Performance of the engine with the EFI system has been generally studied by setting up experimental stations which can test the output speed, torque, air-fuel ratio (AFR), cylinder pressure, and exhaust contents, and the researchers do a lot of experiments to optimize the engine structure or control method $[4,5]$.

Although the engine experiments are designed more and more realistic in recent time, there is still some distance between test results to the real application. In addition, the traditional two-stroke engine test stations are always designed more suitable for the ground vehicles because the test torque is always added by means of electromagnetism, 
which is hard to test the output power of an aeroengine with a propeller. Furthermore, in order to get accurate results, the experiment conditions have to be prepared strictly such as high precision sensors and stable environment, which will greatly increase the research cost. Last but not the least, it is dangerous and inaccurate to simulate extreme working conditions by engine station tests.

Therefore, research studies have paid more and more attention to the engine working process simulation by mathematical models. In order to estimate engine performance such as cylinder pressure, heat release rate, and fuel consumption, Venkatraman and Devaradjane [6] build the working mathematical model of a 4-stroke engine. The simulation model includes cylinder state equation, heat transfer process, ignition delay, combustion duration, and NOx formation. In addition, based on the mathematical model, Venkatraman and Devaradjane [7] design engine experiments for demonstration. In their works, the heat release rate, brake thermal efficiency, carbon monoxide, hydrocarbon, and so on are predicted through the model, and the experiments verify that the rectification model coincides with the reality. Furthermore, in the combustion model, Wiebe heat release function is applied based on the exponential rate of the chemical reactions. Wiebe equations have been implemented by Miyamoto et al. [8], and one of the equation factors is considered to be important which is called "rate of heat release." Ganapathy et al. [9] have employed a thermodynamic model based on two-zone Wiebe heat release function to simulate the performance of new fuel engine. Raut [10] also use an exponential rate-based Wiebe heat release model, and the Pflaum formula is applied in the estimation of empirical coefficient of the heat transfer process. From these works, it can be seen that engine performance study by using the mathematical model method is effective.

GT-Power is the leading engine simulation software based on one-dimensional gas dynamic which represents the flow and transfer in the components of the engine system, and more and more scientists and engineers have applied the computing tool in engine prediction in order to improve the control performance or reduce the emission. Kassa et al. [11] have leveraged experimental data from a 6-cylinder engine to a GT-Power model to better understand the distribution of the port-injected fuel across cylinders under several operating conditions. Rahimi-Gorji et al. [12] have optimized the performance and fuel consumption according to the weather conditions by combining the artificial neural network and GT-Power model, and pressure, temperature, and humidity of the incoming air are considered in the network to obtain a better engine performance. Alves et al. [13] apply GT-Power in the engine intake system design, and the best intake runner length and diameter configuration of each speed for a four-stroke and single cylinder engine is found to get the optimum volume efficiency. Trajkovic et al. [14] build the GT-Power model of a 2-stroke engine to study the effect of different parameters and their effect on pneumatic hybrid performance. From the works above, the mathematical model built by GT-Power is proved to be effective to predict and improve the engine characteristics. However, these papers mainly focus on the engine structure rather than the control strategy of the EFI system.
In order to match the power system of a kind of downsized fuel-powered UAV, the characteristics of the aeroengine, including output speed and output power, should be analyzed based on the GT-Power model with a fixed structure. Furthermore, key control parameters of the matched EFI system should be confirmed for the aeroengine application. Calculations of the engine power based on the GT-Power module have been researched. Yang and Zhu [15] have developed a mixed valve and crank-based engine model for a dual-stage turbocharged engine. Under different loading states, the output torque and released AFR of the engine are simulated, and values of the fuel pulse width are calculated for a reference for the engine control unit (ECU) design. Menacer and Bouchetara [16] have applied the GTPower model to study the effect of the inject fuel mass flow on the brake power and indicate power under the certain ignition advanced angle, compression ratio, and output speed. In their work, the maximum power and economy corresponding to the optimal speed are determined. Wei et al. [17] have adopted a serial of experiment data in a GTPower model of a water-cooled four-stroke engine, and lengths of the opening and closing delay times are optimized, and an optimal inject fuel mass flow is optimized. Moreover, Yang et al. [18] have designed the controlled fuel process and studied the different intake air parameters to improve the engine dynamic performances. However, in these works, the engine confirmatory experiments are far away from the real application of the aeroengine because the torque propeller mainly comes from the propeller air resistance. In addition, some of the works are short of detailed experiment description and relative theory basis, so it is important for us to provide a theoretical model reference for the aeroengine fuel supply system in order to avoid multiple engine parameter tests which can cause huge development costs. Furthermore, ECU controls the injector of the EFI system of the aeroengine, and the electrified injector is opened and atomizes the input high pressure gasoline into the engine manifold [19]. However, because of the electromagnetic force characteristic of the injector, the dynamic response of the injected fuel mass flow will affect the precision of the supplied fuel. Therefore, based on the model results of the theory fuel flow, it is necessary to analyze the dynamic response of the injector and compensate the fuel spray, and then we can get a confirmed EFI control parameter which can provide optimum performance for the aeroengine.

In this paper, we firstly analyze the structure of the aeroengine, and one-dimensional GT-Power mode of the engine is established. Furthermore, several parameter correction methods are proposed. Based on the simulation results of the corrected model, the analytic hierarchy method is applied to optimize the fuel injection control system. Engine experiment results which use the optimize injection MAP demonstrate that the oil consumption rate can be improved differently.

\section{Methodology of Model}

2.1. Subject Introduction. In this paper, the studied twostroke aeroengine with the model of DLE170 has two 
opposing twin cylinders and mainly includes two air cylinders chambers, two pistons, one crankcase, and one crankshaft. As shown in Figure 1, each of the cylinders has a scavenging channel and an exhaust vent, and all the ports are without valves. That means that opening and closing of the holes on the cylinder chambers depend on the movement of the pistons. In addition, main parameters of the aeroengine are shown in Table 1.

When the two-stroke aeroengine starts to work, during the first stroke, firstly, the air-fuel mixture is sucked into the crankcase, and the scavenging port is opened when the pistons move from the bottom dead center (BDC) until the crankshaft rotates to the intake valve closed (IVC) angle, which can be seen in Figure 2. The exhaust port is opened from $\mathrm{BDC}$ until the crankshaft rotates to the emission valve closed (EVC) angle; then, the air-fuel mixture is compressed, and at the ignition advance angle before the top dead center (TDC), the engine is sparked. During the piston power process before the exhaust valve opened (EVO) angle, both the exhaust and scavenging ports are closed, and the cylinder chambers are hermetic which can ensure that the piston gets the maximum power. The ignition advanced angle $(\theta)$ is usually set to 5 15 degrees ahead of TDC. Because the compressed ratio of the engine is relatively high and the rated engine speed is fast, the ignition advanced angle is set at 15 degrees. The fuel in the crankcase comes from the electronic injector as a certain air-fuel ratio $(\lambda)$, and the ratio is determined by the average intake fuel flow $\left(\dot{m}_{\mathrm{f}}\right)$ and air flow into the manifold $\left(\dot{m}_{\operatorname{man}}\right)$, which is controlled by inject fuel pulse width $\left(P_{\mathrm{w}}\right)$, inject fuel pressure $\left(p_{\mathrm{f}}\right)$, and throttle opening degree $(\alpha)$. The relative parameters can also be seen in Table 1.

The engine working process is designed, as shown in Figure 3, according to the working principle of the onedimensional simulation software GT-Power. In this picture, it can be seen that connected to the inlet port there are two symmetrical crankcase chambers with numbers 1 and 2 . When the air-fuel mixture is flows into the crankcase, it is generally assumed that two homogeneous mounts of oil and gas are divided by the crankshaft and then flow into the two cylinders. Furthermore, there are also symmetrical scavenging passages, intake ports, cylinder chambers, exhaust ports, and exhaust passages. The opening and closing degrees of the two kinds of ports determine the intake time of the air-fuel mixture and the exhaust time of the emissions. According to the actual measurement results, the opening areas with the crankshaft angles are as shown in Figures 4(a) and 4(b). It should be noted that, in these figures, range of the $x$-coordinates is 0 to 180 degrees which is in the first working stroke. The changing area with the shaft angle is symmetrical in the second working stroke.

2.2. Modeling Method. Then, the one-dimensional GTPower model of the two-stroke aeroengine can be set, as shown in Figure 5, according to the aeroengine working process. Structure of the aeroengine is based on the actual measure results.

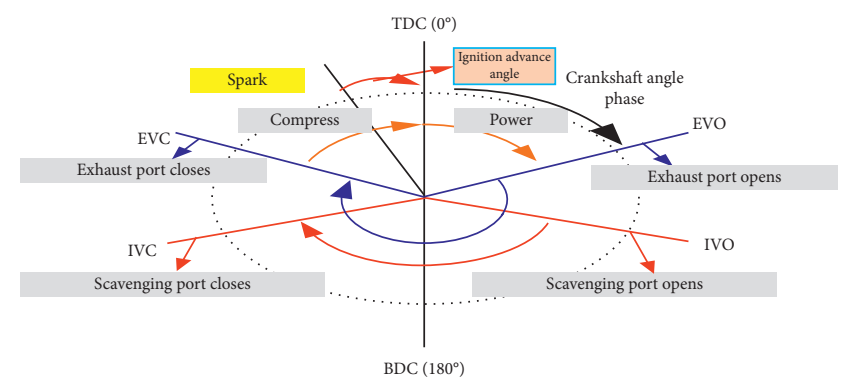

FIgURE 1: Main parts of the two-stroke aeroengine.

TABLE 1: Specifications of DLE170 engine.

\begin{tabular}{lc}
\hline Parameter & Value \\
\hline Cylinder bore (mm) & 52 \\
Engine stroke (mm) & 40 \\
Connecting rod length (mm) & 175 \\
Compression ratio & 9.5 \\
TDC clearance height (mm) & 2 \\
Displacement (cc) & $85 \mathrm{X} 2$ \\
Intake fuel pressure (MPa) & 0.3 \\
EVO (degrees) & 65 \\
IVO (degrees) & 123 \\
Intake pressure (bar) & 1 \\
Intake temperature (K) & 298 \\
Exhaust temperature (K) & 700 \\
Exhaust pressure (bar) & 1.2 \\
Maximum performance & $13 \mathrm{kw}$ \\
Minimum idle (RPM) & $7500 \mathrm{RPM}$ \\
Range of the throttle opening degree (degrees) & 1000 \\
EVC (degrees) & $10 \sim 90$ \\
IVC (degrees) & -65 \\
\hline
\end{tabular}

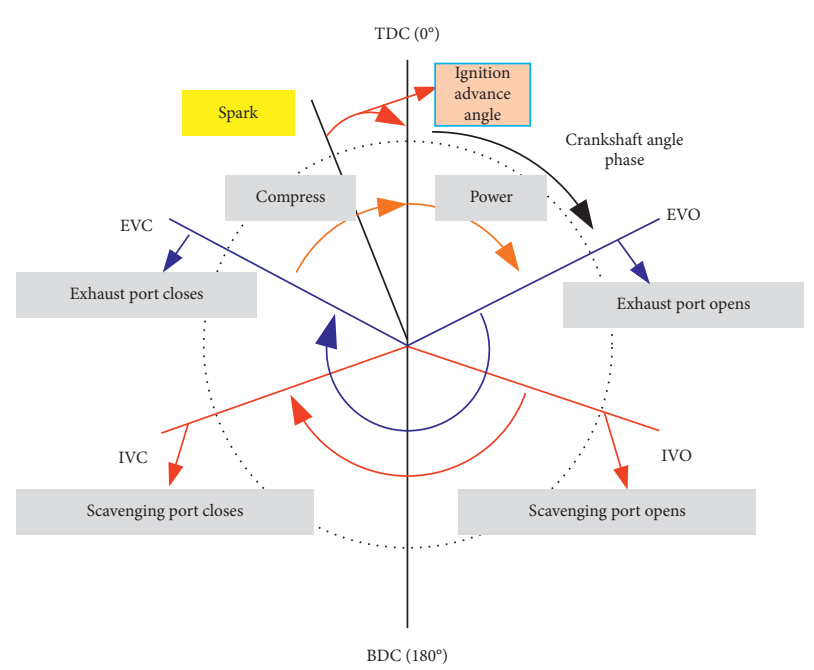

FIgURE 2: Working schematic diagram of the two-stroke aeroengine.

Main setting parameters of the fuel injector are $\dot{\mathrm{m}}_{\mathrm{f}}$ and the set air-fuel ratio $\left(\lambda_{\text {set }}\right)$. In practice, ECU controls the injector work and breaks through pulse signal with a certain 


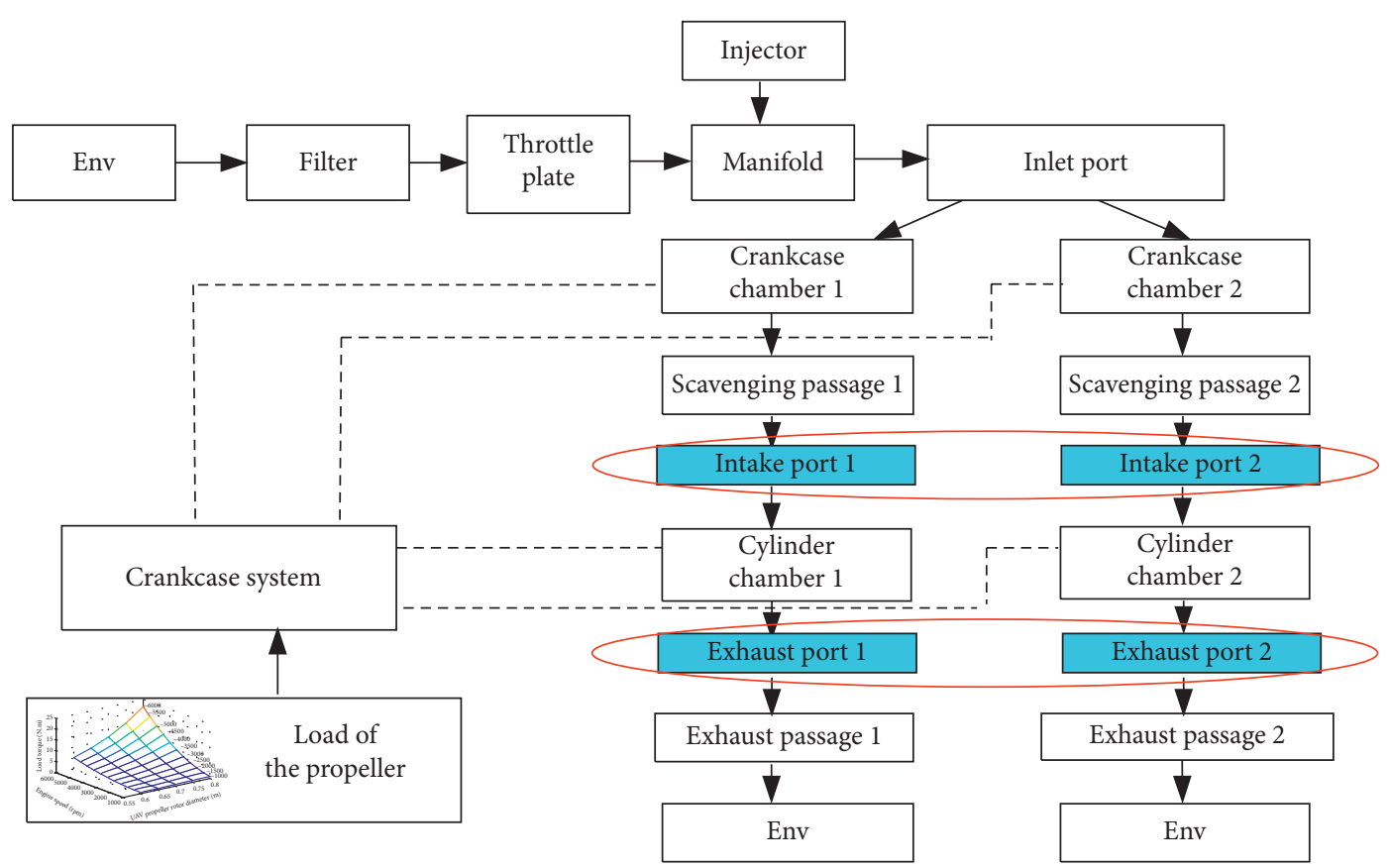

FIGURE 3: Working process of the two-stroke aeroengine.

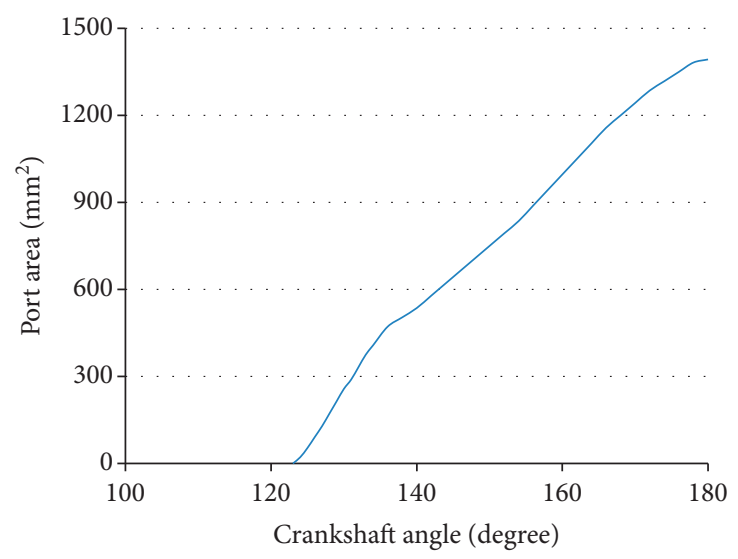

(a)

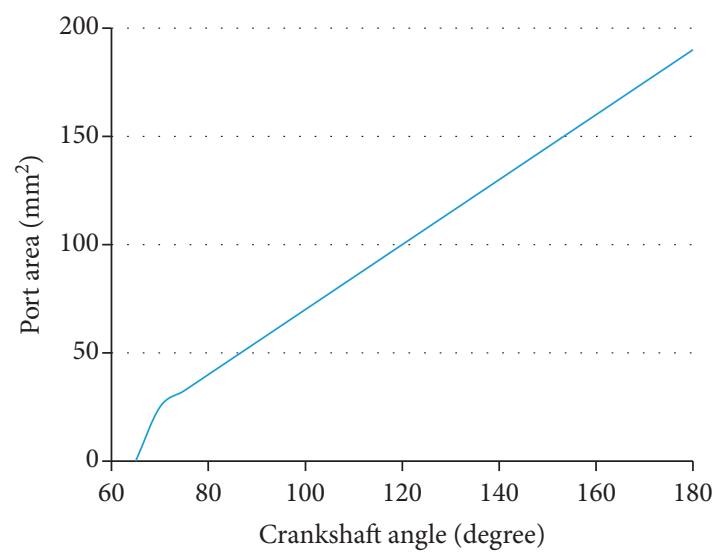

(b)

FIgURE 4: Working process of the two-stroke aeroengine. (a) Intake port area. (b) Exhaust port area.

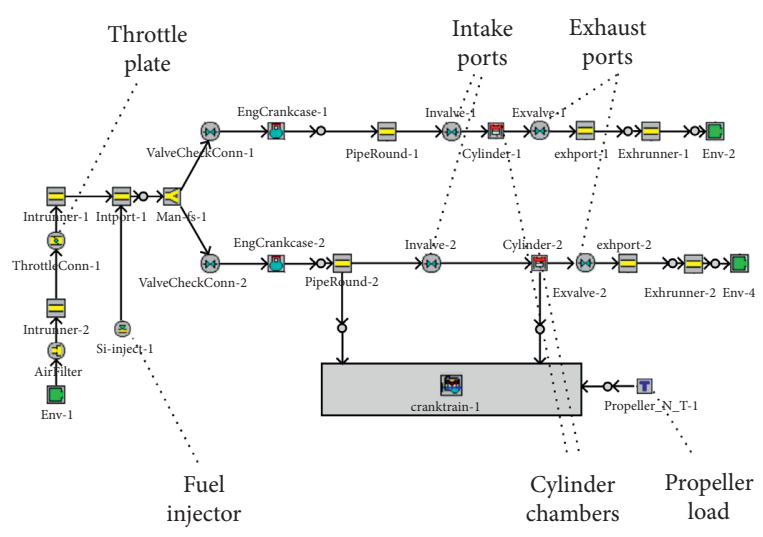

FIGURE 5: One-dimensional GT-Power model of the two-stroke aeroengine. width. Relationship between $\dot{m}_{\mathrm{f}}, \lambda_{\text {set }}$, and the inject fuel pulse width $\left(P_{\mathrm{w}}\right)$ is shown in the following equation:

$$
\dot{m}_{\mathrm{f}}=\frac{\eta_{\mathrm{v}} \rho_{\text {ref }} V_{\mathrm{D}} \lambda_{\text {set }}}{(\# \mathrm{CYL}) P_{\mathrm{w}}}
$$

where $\eta_{\mathrm{v}}$ is volumetric efficiency, $\rho_{\text {ref }}$ is reference air density used to calculate volumetric efficiency, $V_{\mathrm{D}}$ is the engine displacement, and \#CYL is the number of cylinders. From this equation, we can see that $P_{\mathrm{w}}$ directly determines the injected fuel flow. In order to improve the comprehensive performance of the aeroengine, the inject fuel flow rates are calibrated under different working conditions. So, as to make the setup more intuitive, in this paper, the calibrating standard is based on the expected air-fuel ratio, and then the ECU can calculate the output $P_{\mathrm{w}}$ in the real practice. However, because the injector is driven by electromagnetic 
force, the dynamic action of the needle valve should be considered in the compensation of the set pulse width.

Fuel injector working progress mainly includes three steps: the injector receives the pulse signal from ECU, the electromagnetic coil is gradually energized, and the needle valve starts to move when overcoming the spring preload; when the magnetized solenoid coil is saturated, the needle valve stops at the mechanical limit position; when the pulse signal becomes zero, the magnetic flux of the solenoid coil reduces gradually, and the needle valve will return to the normal position. Basically, all the nozzles of the electromagnetic type work in this way, and the response delay impact on the dynamic inject fuel flow caused by mechanical factors cannot be ignored. In order to deeply analyze the dynamic injection and formulate the calibration strategy, the dynamic model of the injector is built as follows:

$$
\begin{aligned}
U_{0} & =R i+N \frac{\mathrm{d} \Phi_{\mathrm{b}}}{\mathrm{d} t}, \quad \text { when electrified, } \\
0 & =\left(R+R_{0}\right) i+N \frac{\mathrm{d} \Phi_{\mathrm{b}}}{\mathrm{d} t}, \quad \text { when not electrified. }
\end{aligned}
$$

These equations are magnetic flux when the injector is electrified and not electrified, where $R$ is the basic resistance of the electrified coil loop, $R_{0}$ is the protective resistance, $\Phi_{\mathrm{b}}$ represents total magnetic circuit, $N$ is the number of the coil, $i$ is the current in the loop, and $U_{0}$ is the driving voltage. The electromagnetic force $\left(F_{\mathrm{m}}\right)$ on the needle valve when the coil is electrified is as follows:

$$
F_{\mathrm{m}}=\frac{\mu_{0}(i N)^{2} S}{2 \delta^{2}}
$$

where $\mu_{0}$ represents permeability of vacuum, $S$ is crosssection of the air gap, and $\delta$ means length of the working air gap. Kinetic equation of the magnetic needle valve is

$$
F_{\mathrm{m}}-F_{0}-k x+F_{\text {fuel }}=m_{\mathrm{v}} \frac{\mathrm{d}^{2} x}{\mathrm{~d} t^{2}},
$$

where $F_{0}$ is the initial tension of spring, $k$ is the spring stiffness, $x$ is the displacement of the needle valve, $m_{\mathrm{v}}$ is the mass of needle valve, and $F_{\text {fuel }}$ is fuel pressure force on the needle valve. When the needle valve is opened, the high pressure fuel erupts and produces spray into the manifold. The equation of the fuel flow is as follows according to orifice compensation principle:

$$
\dot{m}_{\mathrm{fi}}=C_{\mathrm{d}} A_{0} \sqrt{2 \rho_{\mathrm{f}}\left(p_{\mathrm{f}}-p_{\mathrm{m}}\right)},
$$

where $\dot{m}_{\mathrm{fi}}$ is the instantaneous inject fuel mass flow, $C_{\mathrm{d}}$ is discharge coefficient, $A_{0}$ is aperture area, $\rho_{\mathrm{f}}$ is the fuel density, and $P_{\mathrm{m}}$ is the atmosphere pressure. Based on the equations, the dynamic displacement of the needle valve is calculated under different spring stiffness values. As shown in Figure 6(a), when the initial spring tension force $F_{0}$ is set at $5.5 \mathrm{~N}$, the response of the valve displacement will not keep pace with the control signal. However, when $F_{0}$ is set at $9.5 \mathrm{~N}$, pulse width of the needle displacement is much shorter than the control signal, which can be shown in Figure 6(b), and that will lead to insufficient of the inject fuel.
Therefore, the pulse width of the valve displacement can be adjusted to be the same with that of the control signal by setting the spring tension force $F_{0}$. As shown in Figure 6(c), pulse width of the dynamic displacement of the needle valve is approximate to the control signal except at the beginning of the period, where there is a rise process which causes injection control error.

This paper proposes a compensation method for the injection control error. As shown in Figure 7, it can be seen that the displacement compensation time is equal to the current delay time. Compensation area of the rise process is approximate as a triangle. Therefore, the compensation width $\left(P_{\mathrm{c}}\right)$ is shown in the following equation:

$$
P_{\mathrm{c}}=\frac{D_{\mathrm{i}}}{2},
$$

where $D_{\mathrm{i}}$ is the current time delay. Equation (1) can be amended as follows:

$$
\dot{m}_{\mathrm{f}}=\frac{\eta_{\mathrm{v}} \rho_{\text {ref }} V_{\mathrm{D}} \lambda_{\text {set }}}{(\# \mathrm{CYL})\left(P_{\mathrm{w}}+P_{\mathrm{c}}\right)} .
$$

Propeller load can be calculated according to different working conditions based on standard strip analysis. As known from the calculation, load torque of the propeller mainly depends on engine speed $(n)$ and propeller rotor diameter $\left(r_{\mathrm{p}}\right)$. Main formula of the torque is as follows:

$$
M_{\mathrm{R}}=\sum(\Delta D \cos \beta+\Delta L \sin \beta) r_{\mathrm{p}},
$$

where $M_{\mathrm{R}}$ is the propeller torque, $\Delta D$ is differential form of the drag force, $\Delta L$ is differential form of the lift force, $\beta$ is the intake air flow angle, and $r_{\mathrm{p}}$ is the propeller radius. Then, the parameters are confirmed according to a blade material; then, we can get the torque MAP in horizontal direction under different working conditions, which is shown in Figure 8. From Figure 8, we can see that the load torque does not increase linearly with increasing engine speed and the UAV propeller rotor diameter. However, we can substitute the torque MAP into the one-dimensional model by the linear interpolation method.

\section{Experiments and Optimization}

3.1. Experimental Verification. Numerical simulation cannot completely replace experiment analysis, and if we want to make the simulation results reflect the engine mechanism as precisely as possible, the mathematical simulation and experiment analysis should be combined. The mathematical model needs to be verified by experiment results which mainly includes two parts: the engine structure and the combustion model. The engine structure can be verified by intake air flow experiments. That is because the engine is driven by the oil and gas combustion, and if the detected air flow is consistent with the simulation result in different conditions, we can see that the built engine model structure can provide an equal inlet air mass flow. In addition, the combustion model should be demonstrated by the cylinder pressure test. The reason is that the output power of the internal combustion engine mainly comes from the in- 


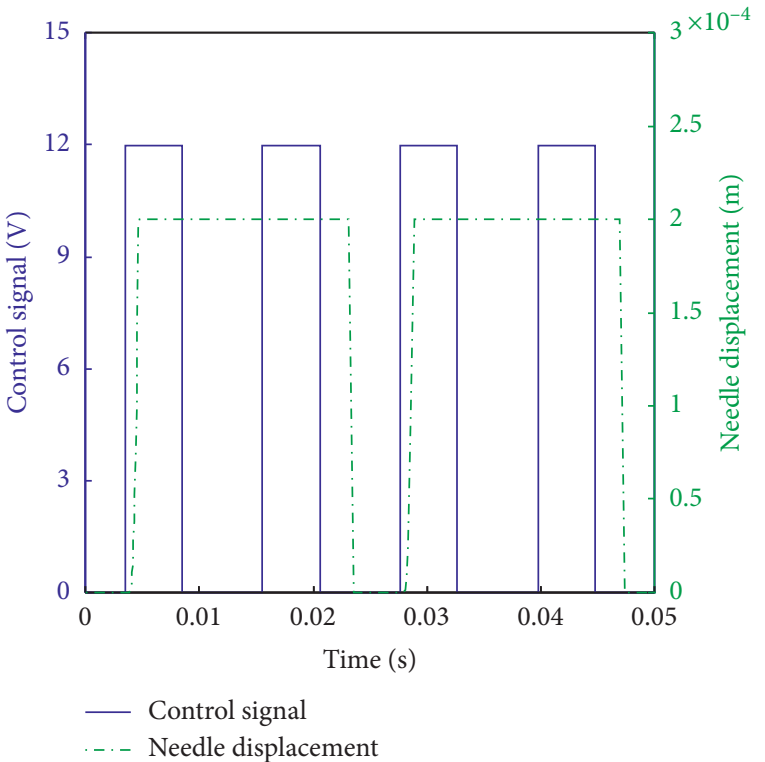

(a)

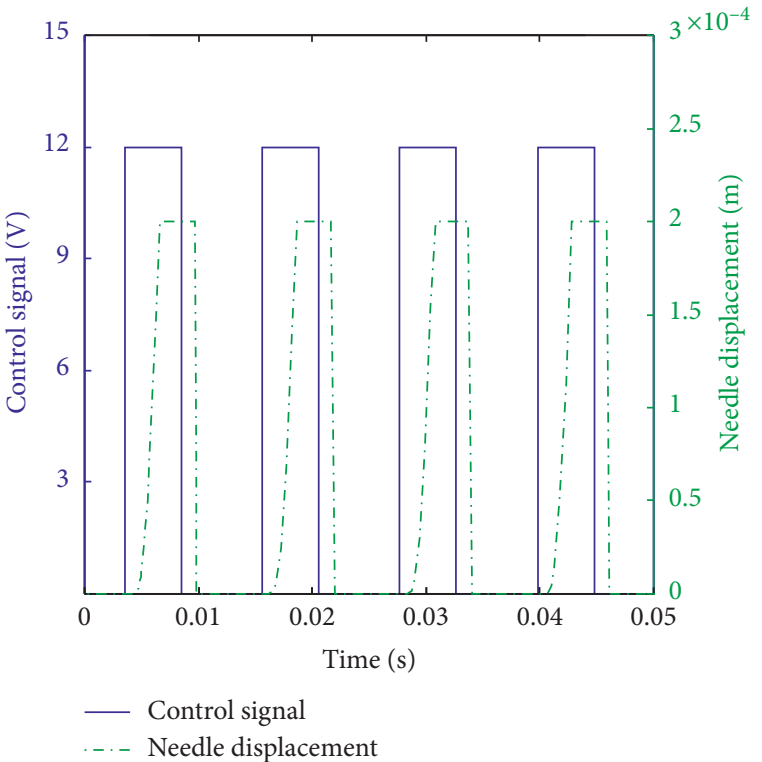

(b)

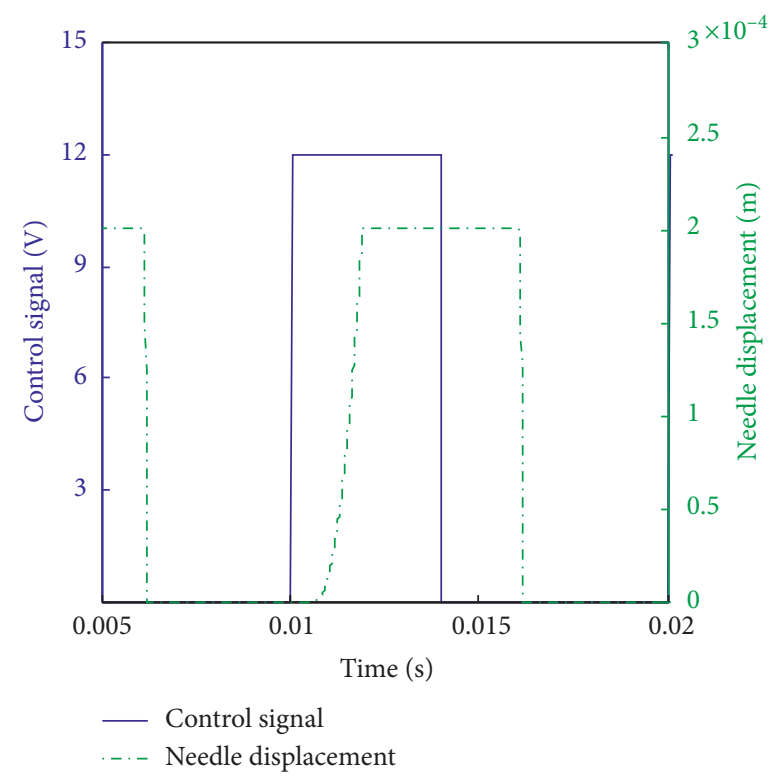

(c)

Figure 6: Dynamic displacement of the needle valve with different spring initial tension $F_{0}$. (a) $F_{0}=5.5 \mathrm{~N}$. (b) $F_{0}=9.5 \mathrm{~N}$. (c) $F_{0}=8.0 \mathrm{~N}$.

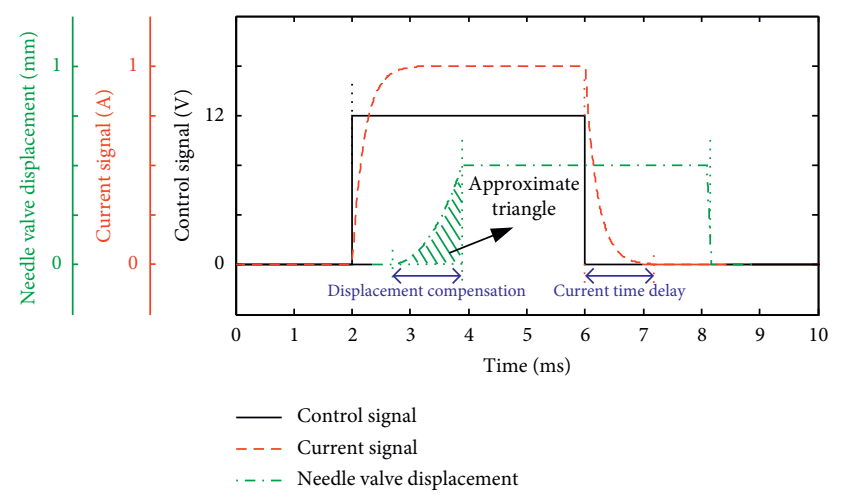

Figure 7: Schematic diagram of needle valve displacement compensation.

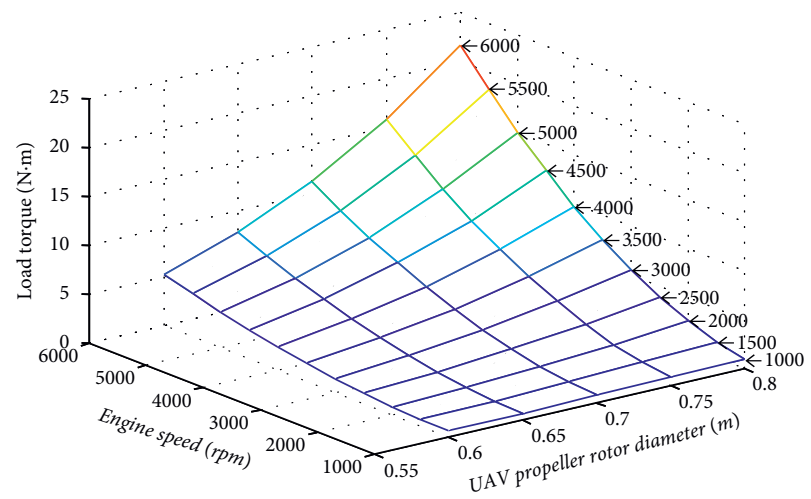

Figure 8: Horizontal torque of the propeller under different working conditions. 
cylinder pressure, and if the detected pressure fits well with the simulation result, it can be seen that the combustion prediction model in the simulation is effective. Therefore, an engine intake air flowmeter is connected with the intake manifold, and a high frequency pressure sensor is setup on the engine cylinder. Then, we can get the air mass flow and cylinder pressure compare curves, as shown in Figures 9(a) and 9 (b). From these two pictures, we can see that the result errors are no more than $5 \%$ and can demonstrate the mathematic model to be effective.

Injection fuel compensation can be demonstrated by ECU experiments. ECU gets trigger signal and outputs pulse signal with a certain pulse width. According to above research result, the inject fuel pulse is compensated by the delay time of the current through the electrified coil loop. According to Figure 10, an ECU with the above function is designed and tested. The current signal as well as the control voltage through the fuel injector is tested. According to Figure 11, we can obtain that the current delay time is about $4 \mathrm{~ms}$. Therefore, in the model, we compensate for the inject pulse by $2 \mathrm{~ms}$. Repetitive experiments with different control signal widths are conducted, and according to the real application, the signal width is controlled within the range of $3.5 \mathrm{~ms}$ to $5.0 \mathrm{~ms}$, and we obtain that the current delay time is the same. That is because their lowering processes of the current are the same. So, in the simulation model, we can set the current delay time as constant $2 \mathrm{~ms}$.

Through the simulation based on the model above, the relative working parameters can be calculated. The basic simulation setting parameters are throttle opening degree $(\alpha)$ and the set air-fuel ratio $\left(\lambda_{\text {set }}\right)$. Generally, the most concerned characteristics and evaluation indicators of the engine mainly include engine speed $(n)$, output power $\left(P_{\mathrm{o}}\right)$, power efficiency $(\eta)$, and rotational fuel consumption $(\gamma) \cdot \eta$ and $\gamma$ can be calculated as follows:

$$
\begin{aligned}
& \eta=\frac{P_{\mathrm{o}}}{P_{\mathrm{i}}}=\frac{n T_{\mathrm{o}}}{9550 \dot{m}_{\mathrm{f}} H_{\mathrm{u}}}, \\
& \gamma=\frac{n}{\dot{m}_{\mathrm{f}}},
\end{aligned}
$$

where $P_{\mathrm{i}}$ is the input power of the engine, $T_{\mathrm{o}}$ is the output torque of the engine, and $H_{\mathrm{u}}$ is the gas calorific value which is about $46000 \mathrm{KJ} / \mathrm{kg}$. By changing the setting parameters $\alpha$ and $\lambda_{\text {set}}$, a group of output parameters are obtained.

3.2. Simulation Results. As shown in Tables 2-4, there are several arrays of input and output parameters. In addition, all the parameters are recorded when the engine simulations tend to be stable.

Tables 2-4 represent a part of simulation results. In this paper, the throttle opening degree $(\alpha)$ is changed from $10^{\circ}$ to $90^{\circ}$, and the engine speed is from $2500 \mathrm{RPM}$ to $6000 \mathrm{RPM}$ according to the real application. What needs illustration is that, according to our a large number of experiment results, the output AFR of the engine can only be controlled within a precision of 0.5, and the general range of AFR during the engine working process is from 12 to 15.5 . Therefore, in the simulation, the input AFR value is set to every 0.5 from 12 to 15.5.

As shown in the three tables, $T_{\mathrm{o}}$ reflects the load-carrying capacity, and generally it is considered as the main indicator of grade ability in the area of ground gasoline. However, in the application of the rotorcraft UAV field, the lift force of the UAV is primarily determined by the engine speed. So, the parameter $T_{\mathrm{o}}$ is mainly considered in the start and acceleration processes. $P_{\mathrm{o}}$ is the output power of the engine, and in the case of the same displacement, output power should be bigger. However, in this paper, the fuel economy is treated as a priority, so in the engine fuel injection control, weight of $\eta$ should be put more. Considering that the engine speed directly influences the lift of the UAV, the rotational fuel consumption $\gamma$ reflects the fuel consumption rate at constant speed. In addition, $P_{\mathrm{c}}$ is the maximum cylinder pressure of one crankshaft rotate cycle.

Since these output characteristics affect each other, the influence rules of the injection parameter should be analyzed in order to assist in the formulation of the optimization strategies. The set AFR directly affects the oil injection flow rate, and its value always combines with that of the throttle opening degree $(\alpha)$. Here, $\alpha$ is controlled stably as $40^{\circ}$ because the single opening degrees value can reflect the whole principle. Engine speed $(n)$ which is as the final control quantity of the UAV power system should be simulated by stages. According to the application requirement, the interval is set as $500 \mathrm{RPM}$ from $2500 \mathrm{RPM}$ to $6000 \mathrm{RPM}$. Then, the tendency charts which show the relationships between the input parameters and the output characteristics are obtained, as shown in Figures 12-15.

As shown in Figures 12 and 13, it can be seen that when the throttle opening degree is constant, the output torque curves, and output power curves will have a peak at a same speed. However, it is difficult to find a regular rule between the set AFR and these two output characteristics. That is because when the throttle opening degree is set constantly, there must be a primal AFR setting value with different working conditions which is in accordance with the engine external characteristics. According to the settled weight, the optimization should be comprehensively considered. In addition, from the two figures, the curve trends are almost the same, so only one of the items can be considered when setting weights in order to reduce the amount of calculation.

It is a bit of mess in Figure 14 which represents the efficiency of the engine system. Curves in Figure 14 almost have peak values, and the peak values basically independent of the output torque and power. Therefore, the characteristic of power efficiency can be considered independently. Power efficiency is significant for the fuel economy improvement. Nevertheless, it should be secondary to the torque and power in the startup and acceleration processes in order to ensure the safety of the UAV flight.

Since the engine speed is kept steady during the flight, the oil consumption of rotation speed $(\gamma)$ is the most important characteristic for fuel saving and flight endurance extension. As shown in Figure 15, the curves have troughs at the same speed point with the torque and power curves. However, in Figure 15, the arrange regular way of the curves 


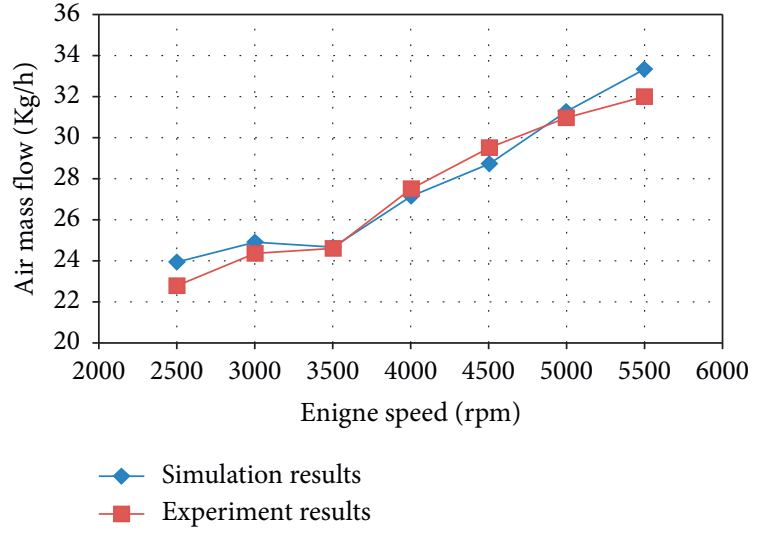

(a)

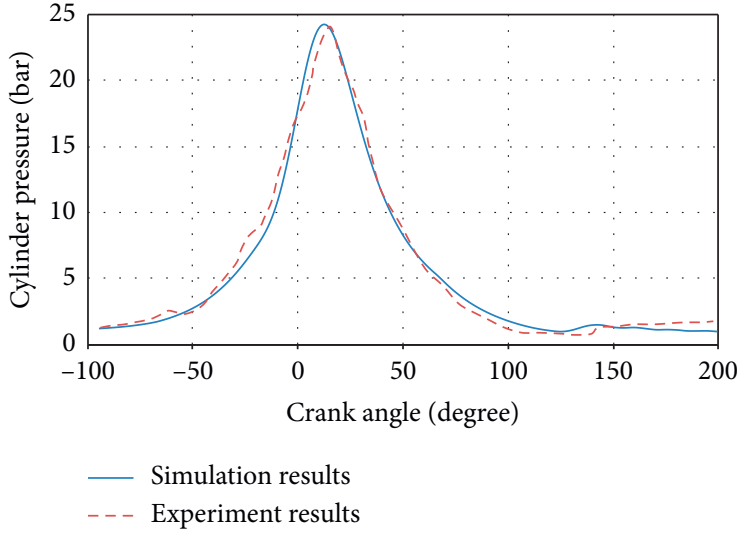

(b)

Figure 9: Air mass flow and cylinder pressure compare curves. (a) Air mass flow at different engine speeds. (b) Cylinder pressure when engine speed is $5000 \mathrm{RPM}$.

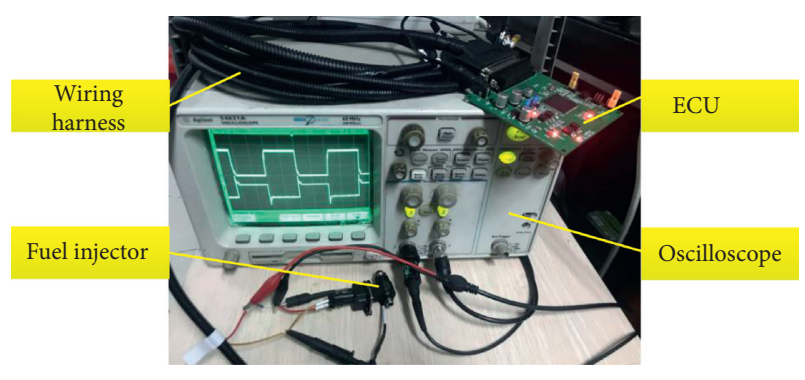

Figure 10: Injector test picture.

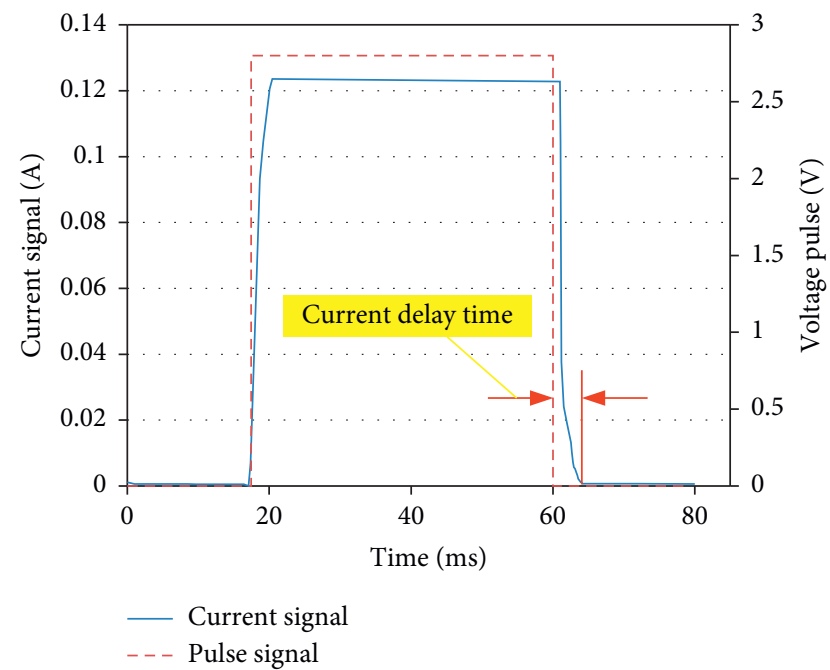

Figure 11: Results of the current delay time test.

of different set AFR values is different from those in Figures 12 and 13. So, in the optimization work, the oil consumption of rotation speed $(\gamma)$ can be independently considered according to the setting weight in the stable flight process of UAV.
TABLE 2: Results of the GT-power simulation when $\alpha=10^{\circ}$.

\begin{tabular}{lccccccc}
\hline $\begin{array}{c}\alpha \\
\left({ }^{\circ}\right)\end{array}$ & $\begin{array}{c}n \\
(\mathrm{RPM})\end{array}$ & $\lambda_{\text {set }}$ & $\begin{array}{c}T_{\mathrm{o}} \\
(\mathrm{Nm})\end{array}$ & $\begin{array}{c}P_{\mathrm{o}} \\
(\mathrm{kw})\end{array}$ & $\eta$ & $\begin{array}{c}\gamma \\
(\mathrm{RPMh} / \mathrm{Kg})\end{array}$ & $\begin{array}{c}P_{\mathrm{c}} \\
(\mathrm{MPa})\end{array}$ \\
\hline 10 & 2500 & 12 & 9.551 & 2.501 & 0.177 & 2257.016 & 3.066 \\
10 & 3000 & 12 & 7.352 & 2.310 & 0.175 & 2892.084 & 2.045 \\
10 & 3500 & 12 & 7.195 & 3.633 & 0.189 & 2316.357 & 2.786 \\
10 & 4000 & 12 & 8.874 & 3.717 & 0.185 & 2537.999 & 3.219 \\
10 & 4500 & 12 & 14.272 & 6.725 & 0.204 & 1736.989 & 3.987 \\
10 & 5000 & 12 & 10.635 & 5.568 & 0.194 & 2219.936 & 2.986 \\
10 & 5500 & 12 & 6.053 & 3.486 & 0.163 & 3280.692 & 2.760 \\
10 & 6000 & 12 & 5.634 & 3.539 & 0.156 & 3362.353 & 2.687 \\
\hline
\end{tabular}

TABLe 3: Results of the GT-power simulation when $\alpha=40^{\circ}$.

\begin{tabular}{lccccccc}
\hline $\begin{array}{l}\alpha \\
\left.{ }^{\circ}\right)\end{array}$ & $\begin{array}{c}n \\
(\mathrm{RPM})\end{array}$ & $\lambda_{\text {set }}$ & $\begin{array}{c}T_{\mathrm{o}} \\
(\mathrm{Nm})\end{array}$ & $\begin{array}{c}P_{\mathrm{o}} \\
(\mathrm{kw})\end{array}$ & $\eta$ & $\begin{array}{c}\gamma \\
(\mathrm{RPM} \cdot \mathrm{h} / \mathrm{Kg})\end{array}$ & $\begin{array}{c}P_{\mathrm{c}} \\
(\mathrm{MPa})\end{array}$ \\
\hline 40 & 2500 & 14.5 & 9.122 & 2.388 & 0.149 & 1987.442 & 3.142 \\
40 & 3000 & 14.5 & 8.869 & 2.786 & 0.140 & 1918.287 & 2.308 \\
40 & 3500 & 14.5 & 12.132 & 4.447 & 0.213 & 2134.503 & 3.228 \\
40 & 4000 & 14.5 & 12.926 & 5.414 & 0.206 & 1934.364 & 3.806 \\
40 & 4500 & 14.5 & 15.451 & 7.281 & 0.179 & 1410.437 & 4.054 \\
40 & 5000 & 14.5 & 13.459 & 7.047 & 0.179 & 1621.358 & 3.952 \\
40 & 5500 & 14.5 & 10.109 & 5.823 & 0.203 & 2445.253 & 3.660 \\
40 & 6000 & 14.5 & 9.111 & 5.725 & 0.165 & 2201.615 & 3.128
\end{tabular}

TABLE 4: Results of the GT-power simulation when $\alpha=80^{\circ}$.

\begin{tabular}{lccccccc}
\hline $\begin{array}{l}\alpha \\
\left({ }^{\circ}\right)\end{array}$ & $\begin{array}{c}n \\
(\mathrm{RPM})\end{array}$ & $\lambda_{\text {set }}$ & $\begin{array}{c}T_{\mathrm{o}} \\
(\mathrm{Nm})\end{array}$ & $\begin{array}{c}P_{\mathrm{o}} \\
(\mathrm{kw})\end{array}$ & $\eta$ & $\begin{array}{c}\gamma \\
(\mathrm{RPM} \cdot \mathrm{h} / \mathrm{Kg})\end{array}$ & $\begin{array}{c}P_{\mathrm{c}} \\
(\mathrm{MPa})\end{array}$ \\
\hline 80 & 2500 & 15.5 & 7.003 & 1.833 & 0.141 & 2453.110 & 2.510 \\
80 & 3000 & 15.5 & 9.582 & 3.010 & 0.194 & 2457.778 & 2.424 \\
80 & 3500 & 15.5 & 11.009 & 4.035 & 0.229 & 2529.551 & 2.974 \\
80 & 4000 & 15.5 & 13.881 & 5.815 & 0.231 & 2020.441 & 3.869 \\
80 & 4500 & 15.5 & 14.826 & 6.987 & 0.167 & 1368.566 & 4.293 \\
80 & 5000 & 15.5 & 12.003 & 6.285 & 0.188 & 1904.895 & 4.107 \\
80 & 5500 & 15.5 & 8.315 & 4.789 & 0.138 & 2018.235 & 3.044 \\
80 & 6000 & 15.5 & 6.094 & 3.829 & 0.205 & 4088.545 & 2.391 \\
\hline
\end{tabular}




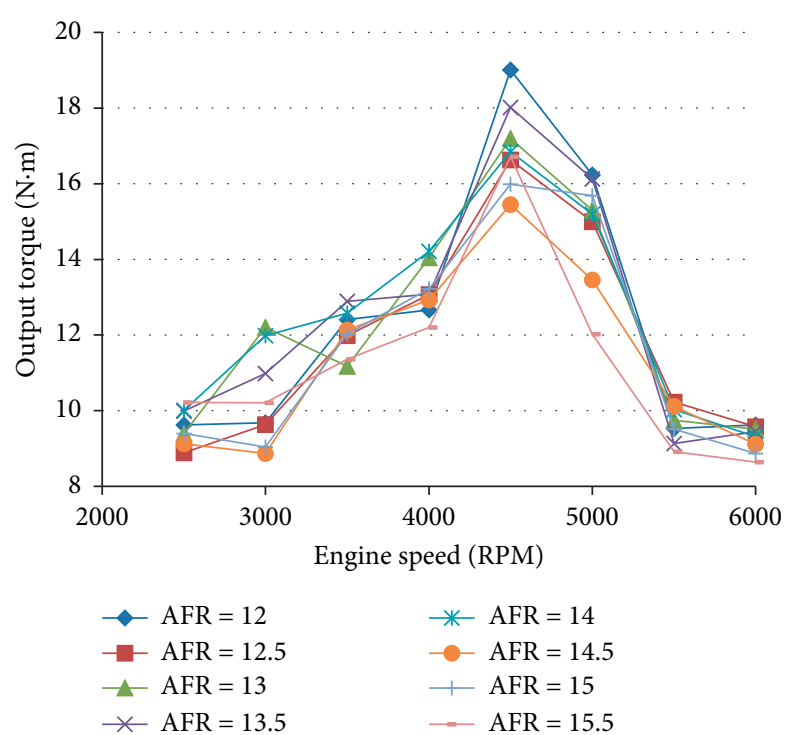

Figure 12: Output torque at different engine speeds.

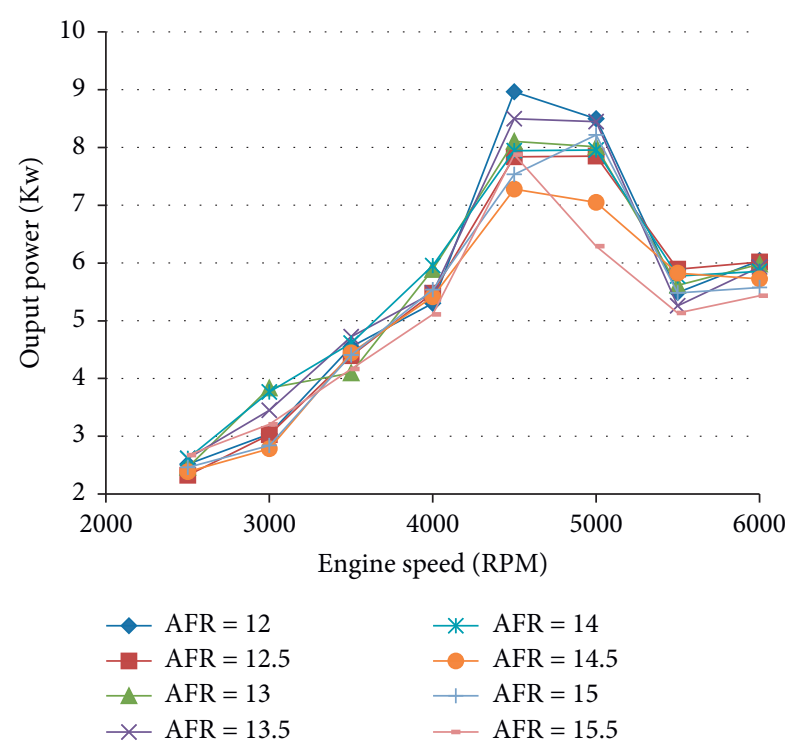

Figure 13: Output power at different engine speeds.

3.3. Optimization Method. Through the improved model, the optimization work is conducted. Several key performance parameters are selected as the multiple optimization objectives, such as output power $\left(P_{\text {out }}\right)$, output speed $(n)$, power efficiency $(\eta)$, and oil consumption of rotation speed $(\gamma)$. In this paper, firstly, we calculate the key characteristics by using the engine model while changing the input engine control parameters. Then, according to the users' requirement, we can artificially set the engine control parameters based on the engine working conditions. The basic principle of the optimization is as the following equations:

$n\left(\alpha_{1}\right)<n\left(\alpha_{2}\right)<\cdots \cdots<n\left(\alpha_{n}\right)\left(\alpha_{1}<\alpha_{2}<\cdots \cdots<\alpha_{n}\right)$,

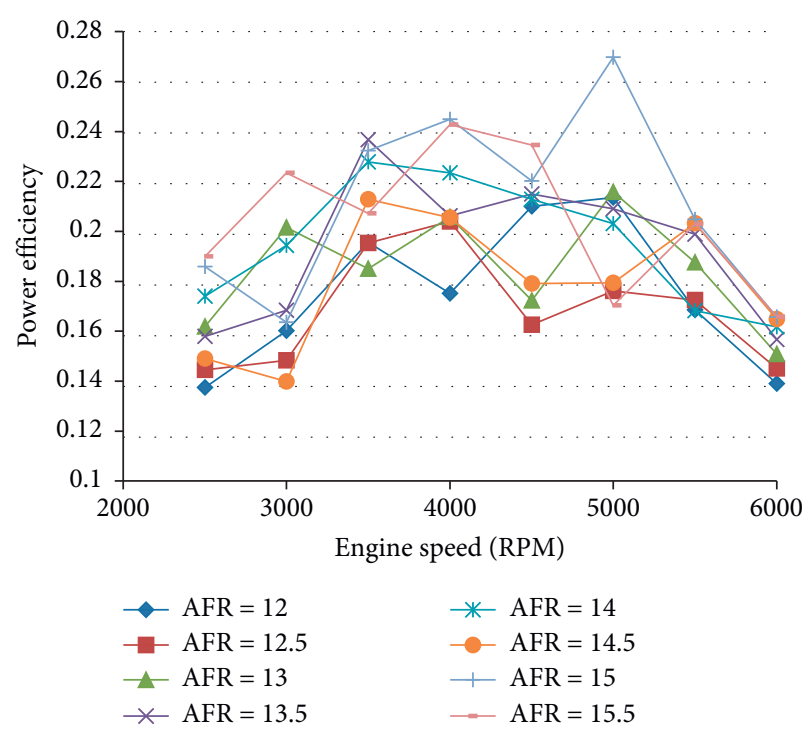

Figure 14: Power efficiency at different engine speeds.

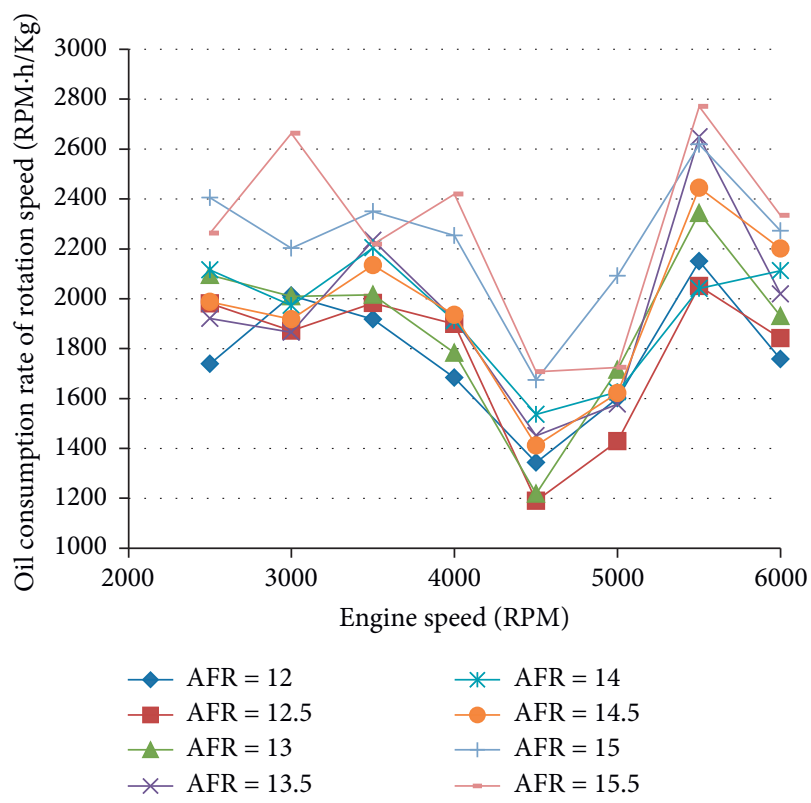

FIgURE 15: Oil consumption rate of rotation speed.

where $n\left(\alpha_{i}\right)(i=1,2, \ldots, n)$ means engine speed with throttle degree of $\alpha_{i}$. Equation (10) represents that the higher the engine speed is risen, the larger the throttle opening degree is. The evaluation system of the set fuel injection parameter relies on the developed evaluation function $f(\theta, n)$ :

$$
f(\theta, n)=\mathbf{W}_{1}(\theta, n) T_{\mathrm{o}}+\mathbf{W}_{2}(\theta, n) P_{\mathrm{o}}+\mathbf{W}_{3}(\theta, n) \eta+\mathbf{W}_{4}(\theta, n) \gamma,
$$

where $\mathbf{W}_{i}(\theta, n)(i=1,2,3$, and 4$)$ represents evaluation weight function of $T_{\mathrm{o}}, P_{\mathrm{o}}, \eta$, and $\gamma$, respectively. In this paper, the weights to be calculated can be expressed as matrixes $\mathbf{W}_{1}$, $\mathbf{W}_{2}, \mathbf{W}_{3}$, and $\mathbf{W}_{4}$, and $\mathbf{W}_{i}(i=1,2,3$ and 4$) \in R^{a \times b}$, where $a$ and $b$ are the numbers of different throttle opening degree values and engine speed values, respectively. Then, the 
matrix of the evaluation function can be expressed as $\mathbf{F}(\theta$, $n) \in R^{a \times b}$. Matrix A is the set AFR matrix. The basic principle of the optimization method is as shown in Figure 16.

The most important step is Step 2 which aims to obtain the weight matrixes. This paper applies a well-known multicriteria decision-making method named Analytic Hierarchy Process (AHP) to obtain evaluation weights for different groups of throttle opening degree and engine speed [20]. The above four alternatives are compared with each other based on self-defined Saaty scale, as shown in Table 5.

According to the experimental experience of the aeroengine characteristics in the application of aircraft flight, principles of setting the weights are as follows:

(a) When the aeroengine starts, the speed gets to idle state, and the throttle degree is relative small, the output power of the engine should be firstly ensured, and oil consumption should be adequate in order to avoid engine speed suddenly dropping.

(b) When the engine works from idle state to intermediate speed (approximate 4000 RPM), according to Figure 8 , the load increase is not obvious. However, the engine noise is big which means the load efficiency is relatively low. The load efficiency is defined as load torque/output torque. At the same time, this process is general when the aircraft takes off and lands, and in order to prevent accidents, the output torque should be primarily guaranteed, and a certain amount of fuel consumption is to be sacrificed.

(c) When the engine speed transits to the rated value, the fuel injection is always controlled based on the output AFR [21, 22]. However, in spite of the relevant regulation of the AFR control, the small aeroengine always leaves out the three-way catalytic unit so as to reduce the whole weight of the aircraft. Therefore, the stoichiometric AFR value is usually not the control target. When the aircraft regularly works, the fuel consumption is the first item to consider because load efficiency of this stage which is relatively high according to the experiment results $[23,24]$. That is because the working noise is regular and varies uniformity along with the rising speed. It can be inferred that it is an uncommon occurrence of drop speed of aeroengine [25, 26]. As for the application in UAV, a certain speed is corresponding to a certain lift force, so the oil consumption of rotation speed $(\gamma)$ should be firstly considered.

(d) When the engine speed is over the rated value, the reason can be, firstly, there is an urgent external disturbance such as mutations in the air, and the flight attitude should be adjusted; secondly, UAV meets the obstacle while moving forward. At this moment, the consideration of output torque and power should be enhanced.

Through the AHP optimizing calculation, the calibration results of fuel injection parameter can be obtained, as shown in Table 6, and the fuel injection MAP is shown in Figure 17.

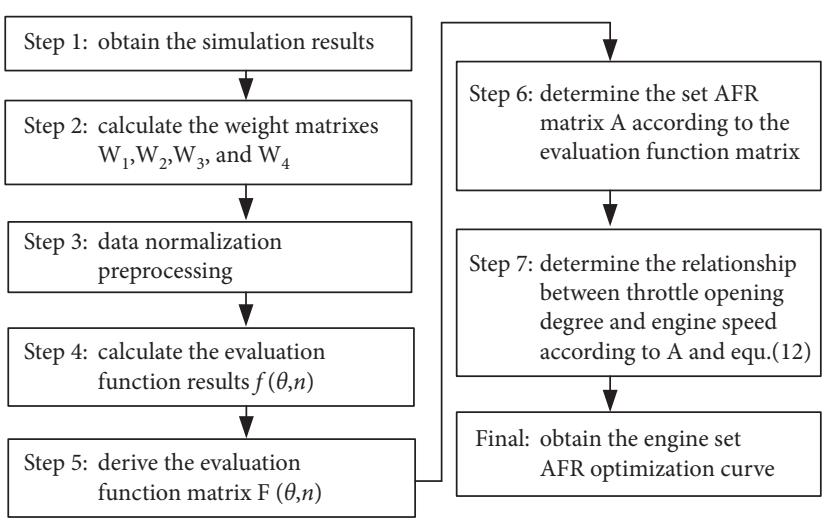

Figure 16: Optimization process.

TABLE 5: Definition and explanation of preference weights based on Saaty's theory.

\begin{tabular}{lcc}
\hline $\begin{array}{l}\text { Preference } \\
\text { weights }\end{array}$ & Definition & Explanation \\
\hline 1 & Equally preferable & $\begin{array}{c}\text { Two factors contribute } \\
\text { equally to the objective } \\
\text { Experience and judgement } \\
\text { slightly favour one over } \\
\text { other }\end{array}$ \\
7 & Strongly preferred & $\begin{array}{c}\text { Experience and judgement } \\
\text { strongly favour one over the } \\
\text { other }\end{array}$ \\
9 & Very strongly & $\begin{array}{c}\text { Experience and judgement } \\
\text { very strongly favour one } \\
\text { over the other }\end{array}$ \\
$2,4,6,8$ & Intermediates values & $\begin{array}{c}\text { The evidence favour one } \\
\text { over the other is of the } \\
\text { highest possible validity } \\
\text { Used to represent } \\
\text { compromise between the } \\
\text { preferences listed }\end{array}$ \\
\hline
\end{tabular}

TABLE 6: Optimize calibration data of fuel injection parameter.

\begin{tabular}{lcccccccc}
\hline$\alpha\left(^{\circ}\right) / n(\mathrm{RPM})$ & 2500 & 3000 & 3500 & 4000 & 4500 & 5000 & 5500 & 6000 \\
\hline 10 & 15.5 & 15 & 15.5 & 15.5 & 15.5 & 15.5 & 15.5 & 15.5 \\
20 & 15 & 14 & 15.5 & 15.5 & 15.5 & 15.5 & 15.5 & 15.5 \\
30 & 14.5 & 12.5 & 15 & 15 & 15.5 & 15.5 & 15.5 & 15.5 \\
40 & 15 & 15.5 & 15 & 15.5 & 15.5 & 15 & 15.5 & 15.5 \\
50 & 15.5 & 15.5 & 12.5 & 15 & 15.5 & 15.5 & 13 & 15.5 \\
60 & 15 & 15.5 & 14.5 & 15.5 & 15.5 & 15.5 & 15 & 14.5 \\
70 & 15 & 15.5 & 15.5 & 15.5 & 15 & 13.5 & 13.5 & 14 \\
80 & 13.5 & 15 & 15 & 15 & 14 & 15 & 14.5 & 15.5 \\
90 & 15.5 & 15.5 & 15.5 & 15.5 & 14.5 & 15.5 & 13.5 & 13.5 \\
\hline
\end{tabular}

From Figure 17, results of the control target of the output AFR of the two-stroke aeroengine of UAV can be summarized as follows:

(1) Engine working conditions are corresponding to different control values in order to achieve the optimal optimization indicator. 


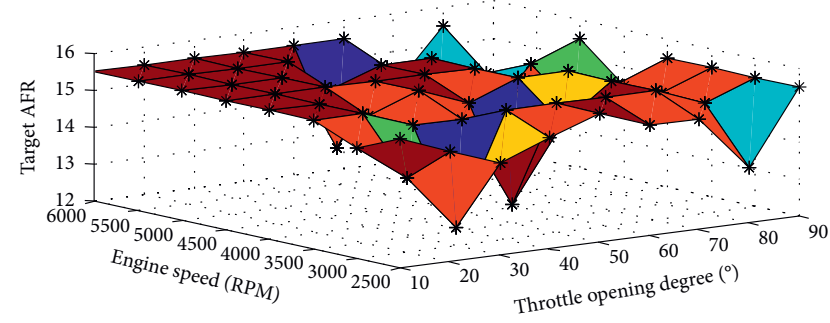

Figure 17: Fuel injection MAP.

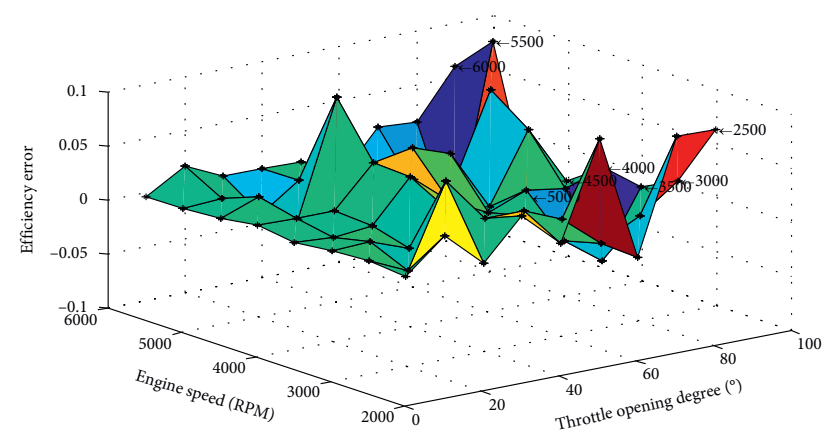

FIGURE 18: Efficiency error MAP.

(2) Through the optimization method based on analytic hierarchy process, efficiency values under the whole working conditions can get a promotion, as shown in Figure 18. At the rated engine working condition (when the engine speed is at the range of 4500 to $6000 \mathrm{rpm}$ ), the improved efficiency is at the range of $5 \%$ to over $10 \%$.

3.4. Optimization Results. Experiments of the aeroengine are designed so as to test the optimal results in the real application. In Figure 19, the analysis computer is connected to a data acquisition card which can gather realtime data from the AFR ratio and engine speed sensors. The oil consumption rate of rotation speed can be calculated according to the collected data including the speed and the fuel consumption within a certain period of time. According to the characteristics of the aeroengine, the power of the load is constant at a certain engine speed. Therefore, in the experiments, the throttle opening degree is stair-stepping settled, and the corresponding oil consumption is recorded.

From Figure 20, results of the aeroengine experiments are obtained through the comparison of the previous open-loop control when the injection width is constantly at $4.5 \mathrm{~ms}$. When the engine speed changes from 3000 to 3500 RPM, the oil consumption rate of the optimal results is higher than that of the previous ones because at lowlevel speed the engine needs more fuel to guarantee the output power when the engine starts. When the aeroengine speed is higher than $4000 \mathrm{RPM}$, the oil consumption rate results of the optimal method are $10 \%$ to $27 \%$ higher than the original results.

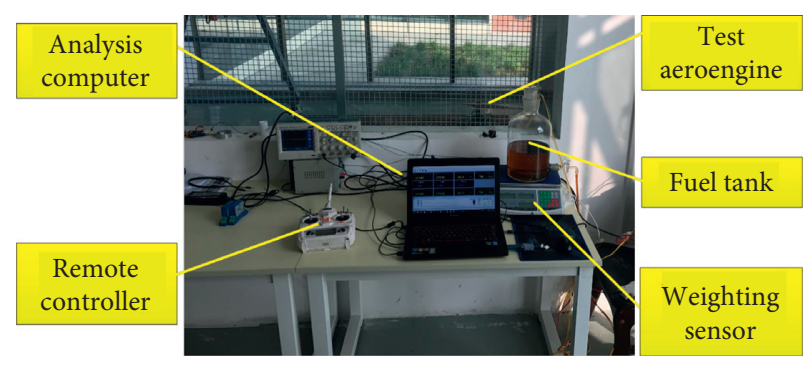

Figure 19: Aeroengine test station.

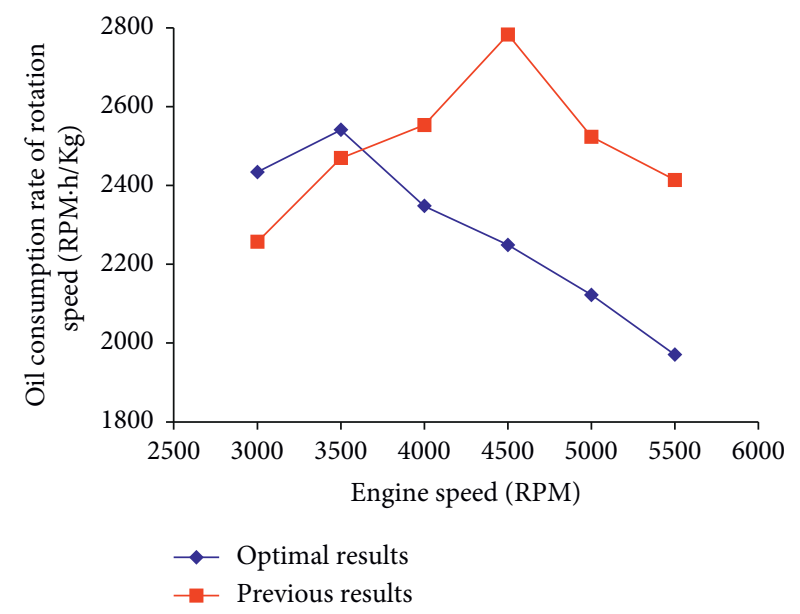

Figure 20: Comparison results of the optimal and previous oil consumption rate of the engine speed.

\section{Conclusion}

This paper proposes a method to optimize the fuel injection control system of two-stroke aeroengine of UAV based on one-dimensional fluid model and analytic hierarchy process. Key parameters of the one-dimensional model are calibrated and verified by calculation reasoning and experimentation. Expert experience is integrated into the rules of the analytic hierarchy calculation process. Through the optimization results from the experiments, it can be seen that when the engine speed changes from 3000 to 3500 RPM, the oil consumption rate of the optimal results is higher than that of the previous ones; when the aeroengine speed is higher than 4000 RPM, the oil consumption rate results of the optimal method are $10 \%$ to $27 \%$ higher than the original results. This method can be a reference for the efficiency optimization of the engine control system.

\section{Data Availability}

The data used to support the findings of this study are included within the article.

\section{Conflicts of Interest}

The authors declare no potential conflicts of interest with respect to the research, authorship, and/or publication of this article. 


\section{Acknowledgments}

This work was supported by the Open Project Funding of Jiangsu Provincial Key Laboratory of Advanced Manufacture and Process for Marine Mechanical Equipment.

\section{References}

[1] C. Stöcker, R. Bennett, F. Nex, M. Gerke, and J. Zevenbergen, "Review of the current state of UAV regulations," Remote Sensing, vol. 9, no. 5, p. 459, 2017.

[2] A. D. Sonparate, S. P. Gadpayle, and P. P. Bajpai, "Performance testing of 2-stroke SI engine by using external vaporized carburetor," International Research Journal of Engineering and Technology (IRJET), vol. 2, no. 8, pp. 14701478, 2015.

[3] H. W. Gitano, R. Chim, and J. Loh, "The application of a resistive type $\mathrm{O} 2$ sensor to a small engine EFI system," in Proceedings of the SAE Technical Paper Series, No. 2014-320073, Pisa, Italy, November 2014.

[4] M. K. Balki, C. Sayin, and M. Canakci, "The effect of different alcohol fuels on the performance, emission and combustion characteristics of a gasoline engine," Fuel, vol. 115, pp. 901906, 2014.

[5] N. Kumar, "Performance evaluation and emission analysis of variable compression ratio direct injection diesel engine," MATTER: International Journal of Science and Technology, vol. 2, no. 2, pp. 32-47, 2016.

[6] M. Venkatraman and G. Devaradjane, "Computer modeling of a CI engine for optimization of operating parameters such as compression ratio, injection timing and injection pressure for better performance and emission using diesel-diesel biodiesel blends," American Journal of Applied Sciences, vol. 8, no. 9, pp. 897-902, 2011.

[7] M. Venkatraman and G. Devaradjane, "Simulation studies of a CI engine for better performance and emission using dieseldiesel biodiesel blends," International Journal on Design and Manufacturing Technologies, vol. 5, no. 2, pp. 14-21, 2011.

[8] N. Miyamoto, T. Chikahisa, T. Murayama, and R. Sawyer, "Description and analysis of diesel engine rate of combustion and performance using Wiebe's functions," in Proceedings of the SAE Technical Paper, Detroit, MI, USA, No. 850107, Detroit, MI, USA, 1985.

[9] T. Ganapathy, K. Murugesan, and R. P. Gakkhar, "Performance optimization of Jatropha biodiesel engine model using Taguchi approach," Applied Energy, vol. 86, no. 11, pp. 2476-2486, 2009.

[10] L. P. Raut, "Computer simulation of CI engine for diesel and biodiesel blends," International Journal of Innovative Technology and Exploring Engineering, vol. 3, no. 2, pp. 2278-3075, 2013.

[11] M. Kassa, C. Hall, A. Ickes, and T. Wallner, "Cylinder-tocylinder variations in power production in a dual fuel internal combustion engine leveraging late intake valve closings," $S A E$ International Journal of Engines, vol. 9, no. 2, pp. 1049-1058, 2016.

[12] M. Rahimi-Gorji, M. Ghajar, A.-H. Kakaee, and D. Domiri Ganji, "Modeling of the air conditions effects on the power and fuel consumption of the SI engine using neural networks and regression," Journal of the Brazilian Society of Mechanical Sciences and Engineering, vol. 39, no. 2, pp. 375-384, 2017.

[13] L. O. F. Alves, M. G. D. dos Santos, A. B. Urquiza, J. H. Guerrero, J. C. de Lira, and V. Abramchuk, "Design of a new intake manifold of a single cylinder engine with three stages," in Proceedings of the SAE Technical Paper, No. 201736-0172, Sao Paulo, Brazil, November 2017.

[14] S. Trajkovic, P. Tunestål, and B. Johansson, "Simulation of a pneumatic hybrid powertrain with VVT in GT-power and comparison with experimental data," in Proceedings of the SAE Technical Paper, No. 2009-01-1323, Detroit, MI, USA, 2009.

[15] X. Yang and G. G. Zhu, "A mixed mean-value and crankbased model of a dual-stage turbocharged SI engine for hardware-in-the-loop simulation," in Proceedings of the 2010 American Control Conference (ACC), pp. 3791-3796, IEEE, Baltimore, MD, USA, 2010.

[16] B. Menacer and M. Bouchetara, "Parametric study of the performance of a turbocharged compression ignition engine," Simulation, vol. 90, no. 12, pp. 1375-1384, 2014.

[17] C. Wei, M. Chen, and Y. Jiang, "Electronic control fuel injection system based on GT-POWER and MotoTron," Procedia Engineering, vol. 174, pp. 773-779, 2017.

[18] X. Yang, C. Liao, and J. Liu, "Harmonic analysis and optimization of the intake system of a gasoline engine using GTpower," Energy Procedia, vol. 14, pp. 756-762, 2012.

[19] J. H. Spurk, T. Betzel, and N. Simon, "Interaction of nonlinear dynamics and unsteady flow in fuel injectors," in Proceedings of the SAE Technical Paper, No. 920621, Detroit, MA, USA, 1992.

[20] T. L. Saaty, The Analytic Hierarchy Process: Planning, Priority Setting, Resource Allocation, McGraw-Hill International Book Co., Columbus, OH, USA, 1980.

[21] Y. Wang, Y. Shi, M. Cai, W. Xu, and Q. Yu, "Optimization of air-fuel ratio control of fuel-powered UAV engine using adaptive fuzzy-PID," Journal of the Franklin Institute, vol. 355, no. 17 , pp. 8554-8575, 2018

[22] Y. Wang, Y. Shi, M. Cai, W. Xu, and Q. Yu, "Efficiency optimized fuel supply strategy of aircraft engine based on airfuel ratio control," Chinese Journal of Aeronautics, vol. 32, no. 2, pp. 489-498, 2018.

[23] Z. Li, C.-Y. Su, G. Li, and H. Su, "Fuzzy approximation-based adaptive backstepping control of an exoskeleton for human upper limbs," IEEE Transactions on Fuzzy Systems, vol. 23, no. 3, pp. 555-566, 2014.

[24] H. Su, C. Yang, G. Ferrigno, and E. De Momi, "Improved human-robot collaborative control of redundant robot for teleoperated minimally invasive surgery," IEEE Robotics and Automation Letters, vol. 4, no. 2, pp. 1447-1453, 2019.

[25] H. Yang, W. Qi, C. Yang, J. Sandoval, G. Ferrigno, and E. D. Momi, "Deep neural network approach in robot tool dynamics identification for bilateral teleoperation," IEEE Robotics and Automation Letters, vol. 5, no. 2, pp. 2943-2949, 2020.

[26] W. Qi and A. Aliverti, "A multimodal wearable system for continuous and real-time breathing pattern monitoring during daily activity," IEEE Journal of Biomedical and Health Informatics, vol. 99, pp. 1-10, 2020. 